\title{
New Trends in Robotic Colorectal Surgery
}

\section{Nicolas C. Buchs*}

Frederic Ris MD, Minoa Jung MD, Philippe Morel MD, Clinic for Visceral and Transplantation Surgery, Department of Surgery, University Hospital of Geneva, Switzerland

Robotic surgery developed exponentially over the last few years, as can testify the increasing number of publications related to this topic [1]. In parallel, in the colorectal field, numerous articles have been published [2], confirming the interest of the surgical community for the robotic approach. Right [3,4] or left [5] robotic colectomy has been reported feasible and safe, even if clear advantages over standard laparoscopy are still awaited and are still a matter of debate [6]. On the other hand, rectal resection might be a better indication for robotics. Indeed, operating in a deep and narrow space is recognized to be challenging by a standard approach. Robotic technology might thus improve the outcomes in this situation. Several authors and reviews have reported very interesting results [2,7], even if a large randomized study is still needed [8].

Recently, robotic single-site surgery has been introduced with success in almost all surgical fields [9]. Thanks to this new robotic platform, robotic single-site cholecystectomy has been proven feasible and safe $[10,11]$, and probably easier than its laparoscopic counterpart [12]. For colorectal resection, the experience is still limited but promising. Even if preliminary, right colectomy has been reported with encouraging results [13-15]. In cases where a specimen extraction is required, a single-site approach might be a good option.

The development of image-guided surgery is another field with growing interest in colorectal surgery. As it was demonstrated for biliary surgery $[16,17]$, the introduction of a new robotic near-infrared camera using indocyanine green (ICG) showed promising results. Indeed, ICG can be used to assess the vascularization of the colorectal anastomosis either by laparoscopy [18] or by robotic surgery as recently reported by Jafari et al. [19]. Indeed, they found a reduction in terms of anastomotic leak (6\% in ICG group versus $18 \%$ in control group) for low anterior resection. In addition, Hellan and colleagues [20] showed that fluorescence imaging provides additional data motivating to change the bowel transection location in $40 \%$ of patients. Moreover, ICG might be useful to identify the sentinel lymph node [21]. If today the exact role of this sentinel lymph node for colorectal cancer is not clearly elucidated, it might be an interesting direction for further research [22]. We could imagine customizing the management according to the result of intraoperative pathology. For example, in case of negative sentinel lymph node, a simple resection might be enough from an oncological point of view, as it was demonstrated for breast cancer. Of course, this strategy is purely hypothetical for colorectal cancer today, but might become a standard of care in a near future. In addition, by associating preoperative radiological images to intraoperative view, augmented-reality or virtual-enhanced world is another developing field of interest. The robotic technology is the perfect interface to create this augmented reality environment, as reported for several other indications [23-25]. For colorectal surgery, we have recently shown the interest of augmented reality for the intraoperative evaluation of the colonic vascularization [26]. The same might be true for ureteral identification.

Another field of interest is the development of robotic transanal surgery for total mesorectal excision (TME). Recently, Atallah et al. [27] have reported their initial experience with this approach that could be interesting for low rectal cancer. Especially in obese male patient, a "reverse" TME might be a good option to avoid an abdominoperineal amputation, while assuring a good distal margin. Obviously, the treatment of selected low rectal tumor is evolving. The development of the transanal resection was seen as a valid option for low grade tumors, especially in comparison to more aggressive treatment (low anterior resection or abdominoperineal resection) [28]. However, the standard trans anal endoscopic microsurgery (TEM) and more recently the transanal minimally invasive surgery (TAMIS) have drawbacks that could be overcome by the robotic technology. Few centers have reported their preliminary experience with this approach $[29,30]$. The results are more than promising and clearly robotic TEM requires larger studies to draw more consistent conclusions.

We live currently a fascinating period of time, especially in the field of robotic colorectal surgery. Many developments and technological innovations are tested every day, often with success. Even if strong evidences are still waited, the driving force and the interest are clearly present and should help to support these efforts.

\section{References}

1. Buchs NC, Pugin F, Ris F, Jung M, Hagen ME, et al. (2013) Robotic general surgery: where do we stand in 2013?. Rev Med Suisse 9: 1317-1322.

2. Aly EH (2014) Robotic colorectal surgery: summary of the current evidence. Int J Colorectal Dis 29: 1-8.

3. Buchs NC, Pugin F, Bucher P, Morel P (2011) Totally robotic right colectomy a preliminary case series and an overview of the literature. Int J Med Robot.

4. D'Annibale A, Pernazza G, Morpurgo E, Monsellato I, Pende V, et al. (2010) Robotic right colon resection: evaluation of first 50 consecutive cases for malignant disease. Ann Surg Oncol 17: 2856-2862.

5. Spinoglio G, Summa M, Priora F, Quarati R, Testa S (2008) Robotic colorectal surgery: first 50 cases e xperience. Dis Colon Rectum 51: 1627-1632.

6. Yoo J (2013) The Robot Has No Role in Elective Colon Surgery. JAMA Surg

7. Baek SK, Carmichael JC, Pigazzi A (2013) Robotic surgery: colon and rectum Cancer J 19: 140-146.

8. Collinson FJ, Jayne DG, Pigazzi A, Tsang C, Barrie JM, et al. (2012) An international, multicentre, prospective, randomised, controlled, unblinded, parallel-group trial of robotic-assisted versus standard laparoscopic surgery for the curative treatment of rectal cancer. Int J Colorectal Dis 27: 233-241.

9. Buchs NC, Pugin F, Volonte F, Jung M, Hagen ME, Morel P (2012) Robotic single site surgery: current practice and future developments. Rev Med Suisse 8: 1316-1320.

*Corresponding author: Nicolas C. Buchs, MD, Clinic for Visceral and Transplantation Surgery, Department of Surgery, University Hospital of Geneva, Rue Gabriel-Perret-Gentil, 41211 Geneva 14 - Switzerland, Tel: +41 79553 2683; E-mail: Nicolas.c.buchs@hcuge.ch

Received January 27, 2014; Accepted January 27, 2014; Published January 29 2014

Citation: Buchs NC (2014) New Trends in Robotic Colorectal Surgery. Adv Robot Autom 3: e117. doi: 10.4172/2168-9695.1000e117

Copyright: ( 2014 Buchs NC. This is an open-access article distributed under the terms of the Creative Commons Attribution License, which permits unrestricted use, distribution, and reproduction in any medium, provided the original author and source are credited. 
10. Morel P, Hagen ME, Bucher P, Buchs NC, Pugin F (2011) Robotic single-port cholecystectomy using a new platform: initial clinical experience. J Gastrointest Surg 15: 2182-2186

11. Morel P, Buchs NC, Iranmanesh P, Pugin F, Buehler L, Azagury DE, et al. (2014) Robotic single-site cholecystectomy. J Hepatobiliary Pancreat Sci 21 : $18-25$.

12. Pietrabissa A, Sbrana F, Morelli L, Badessi F, Pugliese L, Vinci A, et al. (2012) Overcoming the challenges of single-incision cholecystectomy with robotic single-site technology. Arch Surg 147: 709-714.

13. Ostrowitz MB, Eschete D, Zemon H, DeNoto G (2009) Robotic-assisted singleincision right colectomy: early experience. Int J Med Robot 5: 465-470.

14. Morelli L, Guadagni S, Caprili G, Di Candio G, Boggi U, Mosca F (2013) Robotic right colectomy using the Da Vinci Single-Site(R) platform: case report. Int J Med Robot 9: 258-261.

15. Patel CB, Ramos-Valadez DI, Ragupathi M, Haas EM (2010) Single incision laparoscopic-assisted right hemicolectomy: technique and application (with video). Surg Laparosc Endosc Percutan Tech 20: e146-e149.

16. Buchs NC, Hagen ME, Pugin F, Volonte F, Bucher P, et al. (2012) Intraoperative fluorescent cholangiography using indocyanin green during robotic single site cholecystectomy. Int J Med Robot 8: 436-440.

17. Buchs NC, Pugin F, Azagury DE, Jung M, Volonte F, et al. (2013) Real-time near-infrared fluorescent cholangiography could shorten operative time during robotic single-site cholecystectomy. Surg Endosc 27: 3897-3901.

18. Ris F, Hompes R, Cunningham C, Lindsey I, Guy R, et al. (2014) Near infrared (NIR) perfusion angiography in minimally invasive colorectal surgery. Surg Endosc

19. Jafari MD, Lee KH, Halabi WJ, Mills SD, Carmichael JC, et al. (2013) The use of indocyanine green fluorescence to assess anastomotic perfusion during robotic assisted laparoscopic rectal surgery. Surg Endosc 27: 3003-3008.

20. Hellan M, Spinoglio G, Pigazzi A, Lagares-Garcia JA (2014) The influence of fluorescence imaging on the location of bowel transection during robotic leftsided colorectal surgery. Surg Endosc
21. Marano A, Priora F, Lenti LM, Ravazzoni F, Quarati R, Spinoglio G (2013) Application of fluorescence in robotic general surgery: review of the literature and state of the art. World J Surg 37: 2800-2811.

22. Cahill RA, Ris F, Mortensen NJ (2011) Near-infrared laparoscopy for real-time intra-operative arterial and lymphatic perfusion imaging. Colorectal Dis 7: 1217.

23. Buchs NC, Volonte F, Pugin F, Toso C, Fusaglia M, et al. (2013) Augmented environments for the targeting of hepatic lesions during image-guided robotic liver surgery. J Surg Res 184: 825-831

24. Volonte F, Buchs NC, Pugin F, Spaltenstein J, Jung M, et al. (2013) Stereoscopic augmented reality for da Vincii robotic biliary surgery. Int J Surg Case Rep 4: 365-367

25. Volonte F, Buchs NC, Pugin F, Spaltenstein J, Schiltz B, et al. (2013) Augmented reality to the rescue of the minimally invasive surgeon. The usefulness of the interposition of stereoscopic images in the Da Vinci robotic console. Int J Med Robot 9: e34-e38.

26. Volonte F, Pugin F, Buchs NC, Spaltenstein J, Hagen M, et al. (2013) Consoleintegrated stereoscopic OsiriX 3D volume-rendered images for da Vinci colorectal robotic surgery. Surg Innov 20: 158-163.

27. Atallah S, Nassif G, Polavarapu H, deBeche-Adams T, Ouyang J, et al. (2013) Robotic-assisted transanal surgery for total mesorectal excision (RATS-TME) a description of a novel surgical approach with video demonstration. Tech Coloproctol 17: 441-447

28. Ris F, Buchs NC, Hompes R, Morel P (2013) Management of early rectal cancer: total mesorectal excision versus transanal resection? . Rev Med Suisse 9: 1294-1298.

29. Buchs NC, Pugin F, Volonte F, Hagen ME, Morel P, Ris F (2013) Robotic transanal endoscopic microsurgery: technical details for the lateral approach. Dis Colon Rectum 56: 1194-1198

30. Bardakcioglu O (2013) Robotic transanal access surgery. Surg Endosc 27: 1407-1409 